\title{
SEROPREVALENCE AND MOLECULAR DETECTION OF Toxoplasma gondii among WOMEN IN DUHOK PROVINCE/ IRAQ
}

\author{
*Farhad Buzo Mikaeel* and Dr. Adel Talib Mohammed Al-SAeED** \\ ** Dept. of Pathology and Microbiology, College of Veterinary Medicine, University of Duhok, \\ Kurdistan Region-Iraq \\ Dept. of Microbiology, College of Medicine, University of Duhok, Kurdistan Region-Iraq
}

(Received: July 23, 2019; Accepted for Publication: October 14, 2019)

\begin{abstract}
Introduction: Toxoplasmosis is a zoonotic infection of human and animals caused by the protozoan parasite Toxoplasma gondii. The study aimed to detect the seroprevalence of anti $T$. gondii IgG and IgM antibodies and their associated factors in addition to the molecular detection by conventional PCR in women in Duhok Province.

Methods: In the current analytical study, 650 serum samples from women (388 aborted and 262not aborted), were collected randomly between November 2016 and March 2017 in Duhok Province. By using a commercial ELISA kit, IgG and IgM antibodies against $T$. gondii were estimated. In molecular study, DNA was extracted from seropositive samples, then by PCR, B1 gene was amplified and the product visualizes and sent to sequencing.

Results: The study revealed that $28.0 \%$ (182/650) of women were seropositive against anti $T$. gondii IgG antibodies, while $0.46 \%$ (3/650) were seropositive against anti $T$. gondii IgM antibodies, and all the three cases were recorded among women who had contact with cats and seropositive IgG (70.7\% vs. 29.3\%) with significant difference $(\mathrm{P}<\mathbf{0 . 0 0 1})$. Beside to the contacting with cats, residency and occupation had a relationship with seroprevalence of toxoplasmosis in women, in which housewives $(61.4 \%$ vs $38.6 \%)$ with significant difference. $(\mathbf{P}<0.001)$ and women had lived in rural $(69.8 \%$ vs. $30.2 \%)$ with significant difference $(\mathbf{P}<\mathbf{0 . 0 0 1})$ had a higher percentage of seropositive IgG than employee and women those lived in urban respectively, Only $5(8.3 \%)$. serum samples among 60 randomly selected samples from seropositive samples by ELISA were positive by PCR.

Conclusions: The present study showed a considerable percentage of women having toxoplasmosis. The women have a low seroprevalence of IgM, but a higher seroprevalence of IgG antibodies. Contact with cats, residency and occupation have an important role in infection by $T$. gondii.
\end{abstract}

KEYWORDS: Toxoplasma gondii, toxoplasmosis, abortion, pregnancy https://doi.org/10.26682/ajuod.2019.22.2.9

\section{INTRODUCTION}

T oxoplasmosis is a zoonotic infection with worldwide spread among animals and humans. It is caused by the obligate intracellular protozoan parasite $T$. gondii. It can infect all warm-blooded animals and humans. Toxoplasma gondii infections in humans are acquired mainly by consumption of raw or insufficiently cooked meat containing tissue cysts or by ingestion of water or vegetables contaminated with sporulated oocytes shed by infected cats (Dubey and Jones, 2008).

Serological diagnostic tests are considered the first and most widely used techniques for the determination of toxoplasmosis stages. But, the primary and late infection diagnosis during pregnancy is enhanced by Toxoplasma DNA determination (Ghoneim et al., 2009). The importance of Toxoplasma from the perspective of public health is mainly due to the risk of disease transmission during pregnancy. Although toxoplasmosis is often benign in the women, disease transmission through the placenta can lead to serious consequences such as abortion, stillbirth, different degrees of mental or physical retardation, hydrocephalus and blindness (Dubey, 2016).

Natural infection with $T$. gondii generally leads to a state of long-lasting protective immunity (Homan et al., 2000; Leyva et al.,, 2001). The infection is generally diagnosed by 
the presence of specific antibodies to $T$. gondii antigens in the sera of infected host. During acute toxoplasmosis, the presence of Toxoplasma-specific IgM antibodies is the most valuable serological marker and may be detected for a long time after this phase of infection (Marcolino et al.,, 2000).

The present study aimed to detect the seroprevalence of $T$. gondii antibodies in women in Duhok governorate. In addition, to the relationship between the role of some risk factors, such as contact with cats, residency, occupation, age, history and number of abortions and toxoplasmosis. Also, the confirmation of ELISA results by PCR and sequencing were studied.

\section{SUBJECTS AND METHODS Study Design and Sampling}

In the current analytical study, the women attended Duhok Obstetrics and Gynecology Hospital between November 2016 and March 2017were included.

\section{Inclusion and Exclusion Criteria}

The women who were aged 18 years and older and accepted to participate were included in this study. Although, women who were not satisfied were not included in the study.

\section{Data Collection}

The data were collected through two different stages. The general information of the subjects was collected from the women through the selfreported form. In the second stage, the diagnostic information of $T$. gondii was collected through the laboratory diagnostic tests, including serological and molecular methods.

\section{Methods}

Sample collection: Five milliliters of venues blood was withdrawn using a sterile syringe. From each participant, $3 \mathrm{ml}$ was transferred into a fully labeled gel tube (without anticoagulant) and transported to the laboratory. At the laboratory, the serum was separated by centrifugation at $3000 \mathrm{rpm}$ for 5 minutes and stored at $-20 \mathrm{C}^{\circ}$ until used for ELISA. Two $\mathrm{ml}$ of whole blood was collected in a labeled EDTA tube and were stored at $-20 \mathrm{C}^{\circ}$ until used for DNA extraction and PCR analyses.

Questioner performance: A questionnaire form was designed including all of the personal information such as, age, occupation, residence, contacting with cats, number of abortion and abortion history.
Serological Study: Indirect ELISA was performed for the detection of both IgG (Fortress diagnostic TOXO IgG/ Product code: BXE0689A) and IgM (Fortress diagnostic TOXO IgM / product code: BXE0690A) antibodies directed against $T$. gondii in sera according to the manufacturer's instruction. Optical density (OD) values of $>1.1$ and $>0.9$ were taken as positive for $\operatorname{IgG}$ and $\operatorname{IgM}$, respectively.

Molecular Study: DNA was extracted from blood samples that were seropositive by ELISA. Amplification and detection of $T$. gondii DNA by conventional PCR. The primers, targeting the $B 1$ gene, were used according to Homan et.al. (2000), the forward TOX4 (CGCTGCAGGGAGGAAGACGAAAGTTG) and the reverse TOX5 (CGCTGCAGACACAGTGCATCTGGATT).

The total PCR volume of $25 \mu \mathrm{l}$. The reaction mixture contained $12.5 \mathrm{ul}, 2 \mathrm{X}$ HS Prime Taq Premix master rmix (G-7100, GeNet Bio/ Korea) which consisted of 1 unit/10 ul Taq-Pol, 2X reaction buffer $75 \mathrm{mM}$ Tris-HCL (pH 9), $4 \mathrm{mM}$ $\mathrm{MgCl} 2$, and $0.5 \mathrm{mM}$ of each dNTP. The reaction mixture contained $12.5 \mathrm{ul}$ master mix, 10 pmol of each forward and reverse primers, $2 \mu \mathrm{g}$ DNA template, and $8.5 \mathrm{ul}$ RNase free water to a total volume of $25 \mathrm{ul}$ DNA. The cycler condition of PCR was set up at initial denaturation $95{ }^{\circ} \mathrm{C}$ for 4 minutes, then followed by 35 cycles of denaturation $95^{\circ} \mathrm{C} 45 \mathrm{~s}$, annealing $55^{\circ} \mathrm{C}$ for $45 \mathrm{~s}$, extension $72{ }^{\circ} \mathrm{C} 45 \mathrm{~s}$ and final extension at $72{ }^{\circ} \mathrm{C}$ for 5 minutes. Finally, $10 \mu \mathrm{l}$ of PCR products were electrophoresed on $2 \%$ agarose gel and visualized under UV.

Sequencing and Alignment: The PCR products of five samples from each group were sent to Korean (Macrogen) company for sequencing using primers Toxo 4 and Toxo 5. All sequences were applied to NCBI Nucleotide for determination of identity and similarity of the samples. Finally, DNA sequence was submitted to NCBI using BankIt software.

\section{Statistical Analysis}

The mean and standard deviation were used for numerical and frequency and percentage for categorical characteristics of sheep and aborted women. The difference in seropositivity of the parasite in different characteristics of the cases was examined in Pearson Chi-Square and Fishers' Exact tests. The P-value of less than 0.05 was used to reject the null hypothesis. The 
statistical package for social sciences (SPSS version 25:001 IBM: USA) was used for statistical calculations.

\section{IgM Antibodies}

\section{RESULTS}

The study showed that most of the women who were included in this study were in 29-38 age group (44.9\%) and most of them were an employee $(62.2 \%)$ and lived in urban areas $(66.9 \%)$. More than half of them were pregnant $(59.2 \%)$ and 388 aborted (59.7\%) included 379 (57.8\%) with one abortion and $12(1.8 \%)$ with more than one abortion. A small percentage of them were diagnosed to have seropositive $T$. gondii $(0.5 \%)$, and one-third of them had contact with cats $(32.0 \%)$, as shown in Table 1 .

Table (1): General characteristics of studied women

\begin{tabular}{lll}
\hline \multicolumn{1}{c}{ Subjects' Characteristics (n=650) } & Frequency & Percent \\
\hline Age Groups & & \\
18-28 & 284 & 43.7 \\
$29-38$ & 292 & 44.9 \\
$39-48$ & 46 & 7.1 \\
More Than 48 & 28 & 4.3 \\
\hline Occupation & & \\
House Wife & 246 & 37.8 \\
Employee & 404 & 62.2 \\
\hline Region & & \\
Rural & 215 & 33.1 \\
Urban & 435 & 66.9 \\
\hline Abortion & & \\
Aborted & 388 & 59.7 \\
Non-Aborted & 262 & 40.3 \\
\hline Number of abortion & & \\
Non-Aborted & 262 & 40.3 \\
Single & 376 & 57.8 \\
2 Or More Than 2 & 12 & 1.8 \\
\hline Cat Contact & & \\
Yes & 208 & 32.0 \\
No & 442 & 68.0 \\
\hline Results & 3 & 99.5 \\
IgM Positive & 647 & \\
IgM Negative & & \\
\hline
\end{tabular}

The study showed that there is no significant difference in age groups of the women with and without seropositive $T$. gondii $(\mathrm{P}=0.478)$. They were comparable in abortion $(\mathrm{P}=1.00)$, abortion number $(\mathrm{P}=1.00)$, pregnancy $(\mathrm{P}=1.00)$, occupation $(\mathrm{P}=0.054)$, and region where they live $(\mathrm{P}=0.256)$. However, those women who had contact with cats had a higher percentage of sero positive IgM antibodies (100\% vs. $31.7 \%$ ) with non- significant difference $(\mathrm{P}=0.032)$, as presented in Table 2. 
Table (2): Association of IgM seropositivity of Toxoplasma gondii with women's characteristics

\begin{tabular}{|c|c|c|c|}
\hline \multirow[t]{2}{*}{ Women's characteristics $(n=650)$} & \multicolumn{2}{|c|}{ Results } & \multirow[t]{2}{*}{$P$ value } \\
\hline & IgM Positive & IgM Negative & \\
\hline Age & $0(0.0)$ & $284(100.0)$ & 0.478 \\
\hline $18-28$ & $3(1.0)$ & $289(99.0)$ & \\
\hline $29-38$ & $0(0.0)$ & $46(100.0)$ & \\
\hline $39-48$ & $0(0.0)$ & $28(100.0)$ & \\
\hline \multicolumn{4}{|l|}{ more than 48} \\
\hline Abortion & $2(0.5)$ & $386(99.5)$ & 1.000 \\
\hline Aborted & $1(0.4)$ & $261(99.6)$ & \\
\hline \multicolumn{4}{|l|}{ Non Aborted } \\
\hline Abortion Number & $1(0.4)$ & $261(99.6)$ & 1.000 \\
\hline Non-Aborted & $2(0.5)$ & $374(99.5)$ & \\
\hline Single & $0(0.0)$ & $12(100.0)$ & \\
\hline \multicolumn{4}{|l|}{2 or more than 2} \\
\hline Cat Contact & $3(1.4)$ & $205(98.6)$ & 0.032 \\
\hline Yes & $0(0.0)$ & $442(100.0)$ & \\
\hline \multicolumn{4}{|l|}{ No } \\
\hline Occupation & $3(1.2)$ & $243(98.8)$ & 0.054 \\
\hline House Wife & $0(0.0)$ & $404(100.0)$ & \\
\hline \multicolumn{4}{|l|}{ Employee } \\
\hline Region & $2(0.9)$ & $213(99.1)$ & 0.256 \\
\hline Rural & $1(0.2)$ & $434(99.8)$ & \\
\hline Urban & & & \\
\hline
\end{tabular}

\section{IgG Antibodies}

The study showed that $28.0 \% \quad(n=182)$ women who were included in the study were seropositive with anti $T$. gondii $\mathrm{IgG}$ antibodies. The study showed that there was no significant difference in the number of IgG seropositive in women with different age groups $(\mathrm{P}=0.420)$, between the aborted and non-aborted women $(\mathrm{P}=0.809)$ and different number of abortions
$(\mathrm{P}=0.567)$. However, the women with contact with cats had a higher percentage of $\mathrm{IgG}$ seropositive $(70.7 \%$ vs. $29.3 \%)$ with highly significant difference $(\mathrm{P}<0.001)$, housewives $(61.4 \%$ vs. $38.6 \%)$ with highly significant difference $(\mathrm{P}<0.001)$, and those living in rural areas $(69.8 \%$ vs. $30.2 \%)$ with significant difference as shown in Table 3.

Table (3): seropositivity of $\operatorname{IgG}$ in women and its association with general information

\begin{tabular}{|c|c|c|c|}
\hline \multirow[t]{2}{*}{ Women's characteristics $(n=650)$} & \multicolumn{2}{|c|}{ Results } & \multirow[t]{2}{*}{ P Value } \\
\hline & $\begin{array}{c}\text { IgG Positive } \\
182(28.0 \%)\end{array}$ & $\begin{array}{c}\text { IgG Negative } \\
468(72.0 \%)\end{array}$ & \\
\hline Age & & & 0.420 \\
\hline $18-28$ & $88(31.0)$ & $196(69.0)$ & \\
\hline $29-38$ & $73(25.0)$ & $219(75.0)$ & \\
\hline $39-48$ & $14(30.4)$ & $32(69.6)$ & \\
\hline More Than 48 & $7(25.0)$ & $21(75.0)$ & \\
\hline Abortion & & & 0.809 \\
\hline Aborted & $110(28.4)$ & $278(71.6)$ & \\
\hline Non-Aborted & $72(27.5)$ & $190(72.5)$ & \\
\hline Abortion Number & & & 0.567 \\
\hline Non-Aborted & $72(27.5)$ & $190(72.5)$ & \\
\hline Single & $105(27.9)$ & $271(72.1)$ & \\
\hline 2 or More Than 2 & $5(41.7)$ & $7(58.3)$ & \\
\hline Cat Contact & & & $<0.001$ \\
\hline
\end{tabular}




\begin{tabular}{llll}
\hline Yes & $147(70.7)$ & $61(29.3)$ & \\
No & $35(7.9)$ & $407(92.1)$ & $<\mathbf{0 0 1}$ \\
\hline Occupation & & & \\
House Wife & $151(61.4)$ & $95(38.6)$ & \\
Employee & $31(7.7)$ & $373(92.3)$ & $<\mathbf{0 . 0 0 1}$ \\
\hline Region & $150(69.8)$ & $65(30.2)$ & \\
Rural & $32(7.4)$ & $403(92.6)$ & \\
Urban & & \\
\hline Pearson Chi-square test was performed for statistical analyses. & \\
The bold numbers show a significant association. & & \\
\hline
\end{tabular}

The presence of $T$. gondii was confirmed by PCR in blood of studied women in Duhok province. The samples from women, which were seropositive by ELISA (60 seropositive cases were randomly selected) were tested for amplifying $B 1$ gene by using PCR. Five samples out of 60 were positive at a rate of $8.3 \%$ and clearly showed amplicon at around $500 \mathrm{bp}$ (Figure 1). The DNA sequence was aligned to NCBI and it as $100 \%$ identical and similar to
(KX270385). Then the sequence submitted to NCBI, Gene Bank and sequence accepted under accession number

(MK693028.1).

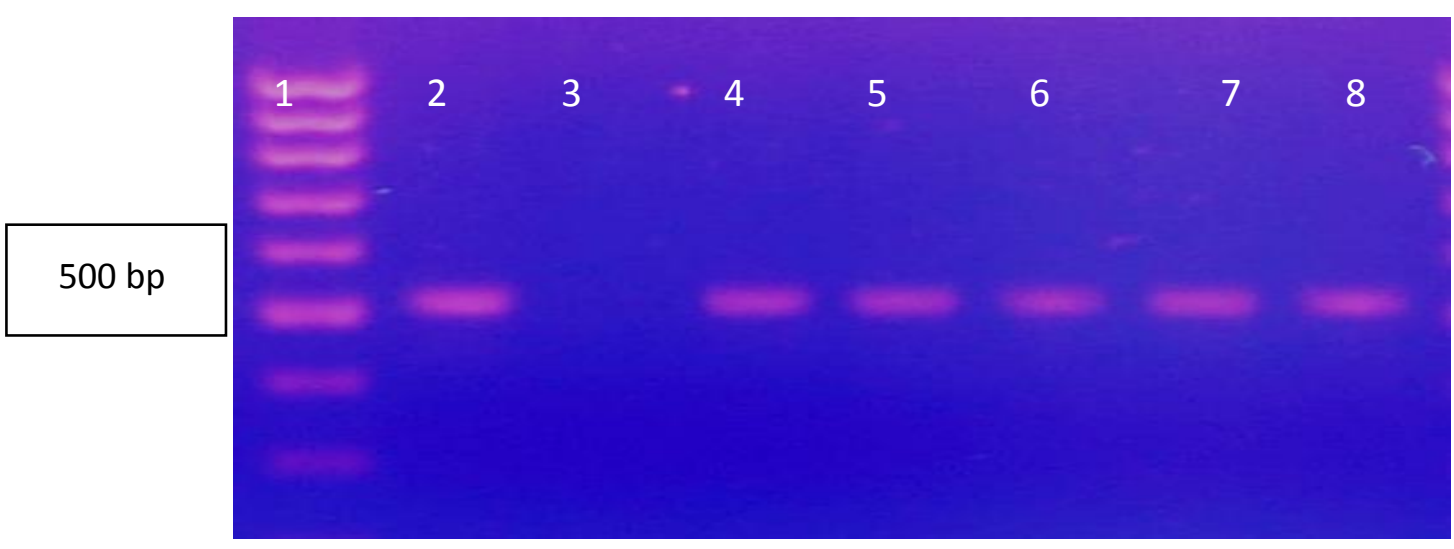

Fig. (1): PCR products of T. gondii on 2\% agarose. Lane $1100 \mathrm{bp} \mathrm{(GeNet} \mathrm{Bio,} \mathrm{Korea)}$ ladder, lane 2 positive control, lane 3 negative control and lanes 4-8 tested samples.

\section{DISCUSSION}

The seroprevalence of toxoplasmosis is variable in different countries worldwide based on the socio-economic standards, patterns of housing, having cats and eating habits of human and animals (Dubey and Jones, 2008).

The present study showed that $28.0 \%$ $(182 / 650)$ of women who were included in this study were seropositive for Toxoplasma $\operatorname{IgG}$ antibodies by indirect ELISA. These results somewhat are consistent with the results of AlAtroshi and Mero (2013)in the same province as they reported a seropositivity rate of $27.7 \%$ toxoplasmosis in women. Somewhat, slightly higher seropositive rates of Toxoplasmosis have been reported in other Iraqi cities and other countries such as, Addor (2011) performed in Salaha-Adden, Mohammed (2011) in Baghdad and Al-Harthi et al., (2006) in Makkah, Saudi Arabia who reported seroprevalence rates of $29.2 \%, 28.77 \%$ and $29.4 \%$, respectively of $T$. gondii infection among women.

However, much higher seroprevalence rates of Toxoplasmosis have been reported from some Iraqi cities such as, Hadi et al. (2016) in Qadisiyah province, Al-Timimi (2004) in Baghdad, Fatohi (1985) in Musol city and Al- 
Attar (2000) in Kirkuk, as they reported rates of $44 \%, 55.26 \%, 52.6 \%$ and $42.6 \%$ respectively. From other countries such as, Sudan $(34.1 \%)$ by Elnahas et al., (2003), in Jordan( $47.1 \%$ ) by Jumaian (2005) and in Zanjan, Northwest of $\operatorname{Iran}(38.6 \%)$ by Hajsoleimani et al., (2012).

The higher seropositivity of $T$. gondii among women in rural resident than those in urban resident, are in accordance with those of Ertug et al.(2005), Ades et al.(1993), Murad et al.( 2016). This finding was similar to that reported in Malaysia (Altunoluk et al.,, 2000) and in Egypt (Attia et al.,, 1995) and in India (Joshi et al.,, 1998) in which they observed that the disease is apparently more prevalent among rural aborted women than those living in urban community, but with no significant difference. The seroprevalence variation between the two communities depends on the basis of poor standards of hygiene and lower socioeconomic status in rural area than in the urban, also rural women are more in contact with domestic and other animals than urban women. The role of risk factors is likely to vary according to cultural habits and climatic conditions affecting the viability of oocysts and their sporulation (Kapperud et al.,, 1996).

Regarding the distribution of Toxoplasma seropositivity according to occupation, it was found that the housewives exposed to infection higher than employee which was $61.14 \%$ seropositive $\mathrm{IgG}$ antibodies. This result is in agreement with Murad et al. (2016) in Duhok, Kadir et al. (2011) in Kirkuk and AL-Waely (1998) in Baghdad, all of them reported higher seropositivity of anti-Toxoplasma antibodies among housewives than employee. The higher rate of infection among housewives might be related to being more in direct contact with infection sources through handling and preparing of meat, vegetables, poor education, in addition to cleaning of house garden contaminated with feces of cats or favorable environmental conditions (Khurana et al., 2010).

Regarding to the history of abortion, the present study showed that the seroprevalence of $T$. gondii was not associated with history of abortion in women, while infection rate was higher in women that aborted more than one time. This result was similar to studies that done in Ninevah governorate by Al-Maqdisy (2000) and Northeast Iran by Babaie et al., (2013), they approved that the rate of infection was higher in women who aborted more than one time. While the result of the present study was disagreed with the result of study which is done by MURAD et al., (2016) in Duhok, which was found that high rate of infection with single abortion.

Regarding to the age, the current study did not find a correlation between toxoplasmosis and age. The results are consistent with those of Ertug et al.(2005), Fallah et al, (2008), Petersen et al. (2010), Mostafavi and Jalali Monfared, (2012), Ertug et al.(2005), they stated that there is no relationship between infection with $T$. gondii and age. On the other hand, the present results disagree with those of Al Hamdani and Mahdi (1997) and Kadir et al. (2011) they stated that the seropositivity of $T$. gondii significantly increased with age.

The low seroprevalence rate $(0.5 \%)$ of antiToxoplama gondii IgM antibodies in pregnant women is in accordance with the studies of Razzak et al. (2005), Al-Atroshi and Mero(2013) and Murad et al. (2016), in Duhok province in which the seroprevalence of $\operatorname{IgM}$ antibodies were $0.97 \%, 0.4$ and $2.9 \%$, respectively by using ELISA. On the other hand, Ali(2018) in Kalar recorded a very high seroprevalence rate $(27 \%)$ of IgM among aborted women and attributed it to the difference in residency, immune status, educational status and socioeconomic status. Generally, IgM antibodies are detected within the first 2 weeks of infection and reduce to low levels within 6 months after infection (Subasinghe et al., 2011).

For the confirmation of ELISA results, 60 seropositive samples were randomly selected for this technique for targeting the $B l$ gene. The results revealed that $5 / 60(8.3 \%)$ were only amplified. The low infection rate by PCR compared to the ELISA results is suggested to be due to the absence of the parasite in the blood at the collection time and the parasite has already localized within the body as a tissue cyst, tachyzoites and/or bradyzoites(Ghoneim et al., 2009).

\section{Strength and Limitations}

The techniques of parasite detection have different sensitivity and specificity. However, the large sample size of the study presents a strong point for the investigation. The seroprevalence reported in the present study may not be generalized to other settings across the country owing to discrepancies. 


\section{Conclusions}

The present study showed a considerable percentage of women having chronic toxoplasmosis. While only $0.4 \%$ of them have acute toxoplasmosis. The higher seroprevalence of $\mathrm{IgG}$ antibodies was associated with some risk factors such as contact with cats, residency and occupation which require special consideration.

Acknowledgments: $\mathrm{We}$ are grateful to the women who accepted to participate in the study and to the health authority for permitting us to get in contact with the patients.

\section{REFERENCES}

Addor, A. Z. R. A. 2011. Seroepidemiological study of Toxoplasmosis among pregnant women in Salah-Adden government. Medical Journal of Tikrit, 1, 66-73.

Ades, A., Parker, S., Gilbert, R., Tookey, P., Berry, T., Hjelm, M., Wilcox, A., Cubitt, D. \& Peckham, C. 1993. Maternal prevalence of Toxoplasma antibody based on anonymous neonatal serosurvey: a geograp hical analysis. Epidemiology \& Infection, 110, 127-133.

Al-Atroshi, A. B. M. and Mero, W. M. S. 2013. Seroprevalence of Anti- Toxoplasma antibodies among women of child bearing age in Duhok Province. Journal of University of Zakho, .1, (A) No.1:.44- 49,

Al-Attar, S. A. 2000. Epidemiological study of toxoplasmosis in Kirkuk city. M. Sc. Thesis, College of Education. Tikrit University.

Al-Harthi, S. A., Jamjoom, M. B. \& Ghazi, H. O. 2006. Seroprevalence of Toxoplasma gondii among pregnant women in Makkah, Saudi Arabia. Umm Al-Qura Univ J Sci Med Eng, $18,217-227$.

Al-Maqdisy, M. 2000. A survey study of the aborted cases in sheep and human caused by Toxoplasma gondii in Ninevah government. MSc. Thesis. College of Veterinary Medicine, Mosul University,(In Arabic).

Al-Timimi, R. 2004. Detection of toxoplasmosis among different groups of aborted women during gestational age of pregnancy. Diploma, Thesis, College of Medical and Health Technology.
Al-Waely, R. 1998. The prevalence of seropositive Toxoplasma gondii antibodies among Iraqi mothers and their new-born babies in Baghdad [The diploma in primary health care.]. Tikrit University: College of Medicine.

Al Hamdani, M. M. \& Mahdi, N. K. 1997. Toxoplasmosis among women with habitual abortion.

Ali, S. I. 2018. Epidemiological Survey of Toxoplasmosis among Aborted Women in Garmian district, Kurdistan Region, Iraq. Kurdistan Journal of Applied Research, 140145.

Altunoluk, B., Akman, M. \& Şahin, İ. 2000. Investigation of anti-Toxoplasma gondii antibodies in women during pregnancy. Türkiye Parazitoloji Dergisi, 24, 343-345.

Attia, R. A., El-Zayat, M., Rizk, H. \& Motawea, S. 1995. Toxoplasma IgG. \& IgM. antibodies. A case control study. Journal of the Egyptian Society of Parasitology, 25, 877-882.

Babaie, J., Amiri, S., Mostafavi, E., Hassan, N., Lotfi, P., Rastaghi, A. R. E. \& Golkar, M. 2013. Seroprevalence and risk factors for Toxoplasma gondii infection among pregnant women in Northeast Iran. Clin. Vaccine Immunol., 20, 1771-1773.

Dubey, J. \& Jones, J. 2008. Toxoplasma gondii infection in humans and animals in the United States. International journal for parasitology, $38,1257-1278$

Dubey, J. P. 2016. Toxoplasmosis of animals and humans, CRC press.

Elnahas, A., Gerais, A. S., Elbashir, M. I., Eldien, E. S. \& Adam, I. 2003. Toxoplasmosis in pregnant Sudanese women. Saudi medical journal, 24, 868-870.

Ertug, S., Okyay, P., Turkmen, M. \& Yuksel, H. 2005. Seroprevalence and risk factors for Toxoplasma infection among pregnant women in Aydin province, Turkey. BMC public health, 5, 66.

Fallah, M., Rabiee, S., Matini, M. \& Taherkhani, H. 2008. Seroepidemiology of toxoplasmosis in primigravida women in Hamadan, Islamic Republic of Iran, 2004. 
Fatohi, F. 1985. Detection of toxoplasmosis among different groups of populations in Mousl city by using IFAT and CFT. M. Sc. Thesis, College of Medicine, University of Mousl.

Ghoneim, N. H., Shalaby, S., Hassanain, N. A., Zeedan, G., Soliman, Y. \& Abdalhamed, A. M. 2009. Detection of genomic Toxoplasma gondii DNA and anti-Toxoplasma antibodies. Journal, Vol, 6.

Hadi, H. S., Kadhim, R. A. \& Al-Mammori, R. T. 2016. Seroepidemiological aspects for Toxoplasma gondii infection in women of Qadisiyah province, Iraq. International Journal of PharmTech Research, 9, 252-259.

Hajsoleimani, F., Ataeian, A., Nourian, A. \& Mazloomzadeh, S. 2012. Seroprevalence of Toxoplasma gondii in pregnant women and bioassay of IgM positive cases in Zanjan, Northwest of Iran. Iranian journal of parasitology, 7, 82.

Homan, W., Vercammen, M., De Braekeleer, J. \& Verschueren, H. 2000. Identification of a 200to 300 -fold repetitive $529 \mathrm{bp}$ DNA fragment in Toxoplasma gondii, and its use for diagnostic and quantitative PCR. International journal for parasitology, 30, 69-75.

Jasim, A. 1979. Seroepidemiological Studies of Toxoplasmosis in Iraq: Evaluation of Serological Tests Used in Diagnosis. A thesis for MSc. Degree in Medical Microbiology, College of Medicine, University of Baghdad.

Joshi, Y., Vyas, S. \& Joshi, K. 1998. Seroprevalence of toxoplasmosis in Jodhpur, India. The Journal of communicable diseases, 30, 32-37.

Jumaian, N. 2005. Seroprevalence and risk factors for Toxoplasma infection in pregnant women in Jordan.

Kadir, M. A., Ghalib, A. K., Othman, N. F. \& Ahmed, I. S. 2011. Seroprevalence of Toxoplasma gondii among pregnant women in Kirkuk/Iraq. kirkuk university journal for scientific studies, 6, 1-11.

Kapperud, G., Jenum, P. A., Stray-Pedersen, B., Melby, K. K., Eskild, A. \& Eng, J. 1996. Risk factors for Toxoplasma gondii infection in pregnancy: results of a prospective casecontrol study in Norway. American journal of epidemiology, 144, 405-412.
Khurana, S., Bagga, R., Aggarwal, A., Lyngdoh, V., Diddi, K. \& Malla, N. 2010. Serological screening for antenatal toxoplasma infection in India. Indian journal of medical microbiology, $28,143$.

Leyva, R., Hérion, P. \& Saavedra, R. 2001. Genetic immunization with plasmid DNA coding for the ROP2 protein of Toxoplasma gondii. Parasitology research, 87, 70-79.

Marcolino, P., Silva, D., Leser, P., Camargo, M. \& Mineo, J. 2000. Molecular markers in acute and chronic phases of human toxoplasmosis: determination of immunoglobulin G avidity by Western blotting. Clin. Diagn. Lab. Immunol., 7, 384-389.

Mohammed, T. K. 2011. Seroprevalence of Toxoplasma gondii among pregnant women in Baghdad city. Al-Taqani, 24, 21-28.

Mostafavi, S. \& Jalali Monfared, L. 2012. Toxoplasmosis epidemiology in Iran: a systematic review. J Isfahan Med School, 176, $1-15$.

Murad, M. A., Eassa, S. H. \& Al-Saeed, A. T. 2016. Detection of toxoplasmosis among women with abortion using molecular and serological tests in duhok city. Duhok Medical Journal, $10,56-68$

Petersen, E., Vesco, G., Villari, S. \& Buffolano, W. 2010. What do we know about risk factors for infection in humans with Toxoplasma gondii and how can we prevent infections? Zoonoses and public health, 57, 8-17.

Razzak, A., Wais, S. \& Saeid, A. 2005. Toxoplasmosis: the innocent suspect of pregnancy wastage in Duhok, Iraq.

Subasinghe, S., Karunaweera, N., Kaluarachchi, A., Abayaweera, C., Gunatilake, M., Ranawaka, J., Jayasundara, D. \& Gunawardena, G. 2011. Toxoplasma gondii seroprevalence among two selected groups of women. Sri Lankan Journal of Infectious Diseases, 1. 